Acta Poetica $32 \cdot 2$

JULIO-DICIEMBRE

2011 (257-272)

\title{
El amor en las obras juveniles de Dante y de James Joyce
}

Quizás el acercamiento entre dos obras, la Vita Nuova que Dante escribió entre 1292 y1293 y A Portrait of the Artist as a Young Man de James Joyce, de 1904, separadas por tantos siglos y escritas en contextos tan diferentes, pueda parecer descabellado y arbitrario. Sin embargo, una reciente relectura de la novela de Joyce me reveló con asombro reminiscencias y alusiones a la fenomenología amorosa del Dolce Stil Nuovo y de la poesía amorosa de los ducentisti (siglo XIII) florentinos, sobre todo de Dante y de Cavalcanti, con quienes Joyce estaba muy familiarizado. ¿Se trata de una coincidencia, que de todas maneras confirmaría la persistencia por siglos del sentimiento amoroso de origen cortés, o más bien de una referencia precisa a la poesía estilnovista? En mi opinión, Joyce acudió intencionalmente a Dante y Cavalcanti. Su conocimiento de la poesía estilnovista, su consonancia con los líricos florentinos del siglo XIII, los Fedeli d'amore - de los que Joyce en su Retrato del artista adolescente utiliza tópicos, estilemas y cadencias - ayudaron al protagonista Stephen Dedalus a tomar conciencia de la ambivalencia amorosa entre el deseo carnal y el amor platónico que lo desgarraba, a vivirla existencialmente y superarla.

En 1949, el dantista estadounidense Charles Singleton dedicó un Ensayo sobre la Vita Nuova a la dificultad de acercamiento que hoy presenta el texto del joven Dante. Aun reconociendo que la Vita Nuova trasciende su momento histórico, afirma que el mundo dantesco está muy alejado del nuestro, no tanto por razones de distancia cronológica sino de horizonte, pues el arte y la poesía medievales están impregnados de ideas y sentimientos cristianos ya ajenos a nosotros. Falta, pues, la tensión entre la obra y su contexto público, 
y falta porque el mundo medieval se hizo pedazos. ¿Qué significado puede tener el microcosmos de la Vita Nuova, se pregunta Singleton, si no está acompañado dentro de nosotros por una percepción, aun mínima, del mundo en el momento de su creación? Entonces, si queremos acercarnos a la Vita Nuova o a cualquier otra obra medieval debemos esforzarnos por regresar a aquellos tiempos y acomodar nuestros ojos a una manera distinta de ver. Hoy, a más de medio siglo de distancia, la lejanía que señalaba Singleton se hace más profunda, porque al eclipse de lo sagrado y a la secularización siguió la liberación sexual, que rompió con el mito del amor cortés, del amor inaccesible e insatisfecho que gobernó a Occidente desde que a principios del segundo milenio empezaron a cantarlo los trovadores del mediodía francés. Los protagonistas de ese mito, que pasó al norte de Francia en el roman courtois de los troveros -Tristán e Isolda, Ginebra y Lanzarote - y posteriormente a toda Europa, adquirieron dimensiones arquetípicas y dejaron una huella de siglos en el imaginario occidental, según la célebre tesis del cuestionado Denis de Rougemont, en cuya línea se halla La llama doble de Octavio Paz.

Ahora se gesta una nueva forma de amar, y con ella una concepción distinta del amor que sustituirá a la antigua, cuyo desarrollo no podemos prever. Sin embargo, en la narrativa de la primera mitad del siglo xx, la relación con el mito amoroso del Dolce Stil Nuovo y de la Vita Nuova todavía está presente en la novela autobiográfica que James Joyce escribió a los 22 años, en 1904, que luego reestructuró en 1907 y 1914 y finalmente se publicó en los Estados Unidos en 1916, con el título A Portrait of the Artist as a Young Man. Las reminiscencias estilnovistas, sobre todo de la poesía de Dante y del "sombrío" Cavalcanti, comprueban que Joyce estaba familiarizado con los poetas florentinos del Duecento. A la aparición "epifánica" de la muchacha-ave, "ángel de terrenal belleza", al final del capítulo cuarto del Retrato, contrapunto del ángel bajado del cielo para miracol mostrare (mostrar milagro) de los poetas del Dolce Stil Nuovo, siguen alusiones bastante claras a la fenomenología amorosa estilnovista. Esta permitió a Joyce-Stephen, insistimos, hacerse consciente de la ambivalencia amorosa que lo desgarraba, encontrar una consonancia con el conflicto que él mismo vivía. 
Con la Vita Nuova, Dante Alighieri debuta en el movimiento poético de los Fedeli d'amore que se conoce como Dolce Stil Nuovo. Este movimiento suscitó de inmediato iras y protestas de la generación anterior de poetas, quienes consideraron al nuevo estilo como un laido errore ('feo error'). Se levantó pues en Florencia y en toda la Toscana una violenta querella entre dos generaciones, una tensión poética desplegada en una incesante correspondencia en forma de sonetos rebosantes de acrimonia. El tema de la poesía de ambas generaciones es común: el Amor. Pero es el "modo", afirman los estilnovistas, el que cambia. Difieren contenido y forma; las palabras viejas asumen un significado nuevo, como dice Franceso De Sanctis. El amor objeto del canto poético estilnovista no es el exterior, material, artificial de un Guittone d'Arezzo o de un Bonagiunta, sino una experiencia interior. Los nuevos poetas - Guinizzelli, Cavalcanti, Dante, Cino da Pistoia, etc.- atacan la vieja poesía consagrada, criticándola como ampulosa, fría, artificial; en una palabra, falsa, porque no obedece el verdadero dictado de Amor, lo que el amor "dicta dentro", como dice Dante: hecho interior que debe analizarse, al que hay que obedecer con sinceridad y precisión, registrando el "modo" como se manifiesta y los efectos que produce en el alma gentil. Esto hacen los poetas per altezza d'ingegno ('por grandeza de ingenio') y no por nobleza de sangre, y con una sutileza psicológica que les viene de la lección de la Escolástica y de la cultura científica y filosófica adquirida en las universidades.

El origen de la poesía florentina y toscana está en el amor cortés de los trovadores en la lengua de Oc del mediodía francés, nacido en las grandes cortes de Occitania, así como de la escuela siciliana bajo el imperio de Federico II de Suecia. De hecho, cuando la violenta cruzada de la Iglesia contra los herejes albigenses termina destruyendo la cultura occitana en el momento de su apogeo, muchos trovadores se refugian en Italia, sobre todo en Sicilia, en la Magna Curia de Federico II. Ahí, el amor es cantado por el mismo emperador y sus funcionarios en forma del soneto inventado por Giacomo da Lentini, forma que se difundirá en la Toscana y luego al resto del continente. Como dice Erich Auerbach, el efecto más profundo de la espiritualidad medieval es la sublimación del amor sensible, que 
apareció en Provenza y se volvió elemento constitutivo de la poesía europea de todos los tiempos.

Es evidente que al trasplantarse a otros terrenos, el amor cortés o la fin'amor, como lo llamaron los trovadores, adquiere caracteres propios. El mundo al que se trasplanta en la Toscana no es el feudal de Occitania o Sicilia, sino el de una burguesía en la fase "heroica" del capitalismo, o precapitalista, en cuyo ambiente realista el sentimiento amoroso sufre una transformación espiritual antes desconocida y se despliega acompañado por un movimiento cultural deslumbrante. Paradójicamente, la literatura italiana, nacida con retraso respecto a las letras romances de Francia y España, con Tomás de Aquino y Dante lleva la cultura medieval a su apogeo conclusivo. En ese escenario efervescente, el amor va "limándose" - uso una expresión estilnovista - hasta asumir una nueva fisonomía y llegar a su sublimación en la Vita Nuova de Dante. La mujer, que en la poesía de la lengua de Oc es un ser terrenal, en la del Dolce Stil Nuovo se torna mediadora de conocimiento y de purificación interior, intermediaria y guía hacia la trascendencia divina.

El paso de las cortes del mediodía francés y de la Magna Curia a la Toscana lleva pues a un contexto completamente distinto, en donde la transformación es muy profunda y en el que debemos detenernos. Los valores proclamados por la nueva poesía amorosa son idénticos: la idealización de la mujer amada y su inaccesibilidad son imágenes tomadas de la tradición no solo occitana sino siciliana, pero intensificados por la nueva concepción del amor como anhelo a la perfección y a la virtud. La poesía mantiene su espíritu aristocrático al tiempo que elimina todo carácter clasista, privilegio de la nobleza de sangre, y lo amplía a una aristocracia de mentes elevadas, nobles per altezza d'ingegno, como dice Dante.

Otra novedad acentúa la transformación del sentimiento amoroso. La doctrina del amor gentile nace en las universidades, entre intelectuales, en un ambiente científico, loico - como proclamaba Dante--; es decir, el de cultores de la lógica, de la filosofía. Guinizzelli, Cavalcantti, Dante y Cino da Pistoia estudiaron en la universidad de Bolonia, y en esa universidad nace la doctrina del amor gentile; de allí irradia a la Toscana, con aquel Guido Guizzelli, poeta además de jurisconsulto, cuya canción doctrinal en lengua vulgar Al cor gentil 
rempaira sempre amor inaugura el nuevo sentimiento del amor como gentilezza, como potencia que puede volverse acto en el corazón gentil, de nobles sentimientos. Pocos decenios después Dante retoma en su Vita Nuova el tema de la gentileza: "Ne li occhi porta la mia donna Amore, / per che si fa gentile ch'ella mira” ('Mi amada lleva Amor en los ojos, y por eso lo que mira se hace gentil'), y en otro soneto: "Amor e'l cor gentile son una cosa, / si come il saggio in suo dittare pone" ("Amor y corazón gentil son una cosa, así como dice el sabio en su dictar'). El "sabio" es Guinizzelli, a quien Dante rinde homenaje en el Purgatorio, llamándole:

il padre mio a delli altri miei miglior che mairime d'amore usar dolci a leggiadre. ${ }^{1}$

('el padre mío y de los demás que mejor usaron rimas de amor dulces y hermosas')

Sin embargo, Guinizzelli reconoce que el precursor de la poesía amorosa en el campo europeo fue Arnaut Daniel, el miglior fabbro del parlar materno ('el mejor artífice del habla materna'), y en boca de este Dante pone, en lengua de Oc, los versos finales del canto.

El ambiente cultural estilnovista, como se dijo, está embebido de la filosofía escolástica. El dominico Tomás de Aquino y el franciscano Bonaventura da Bagnareggio habían muerto recientemente, dejando huella también en la poesía. La aparición de la Cántica de las criaturas de Francisco de Asís (1226-1281) es el primer monumento poético en lengua vulgar. Francisco, quien practica el amor cristiano "sin glosas", deja su huella en el imaginario italiano y muda profundamente la sensibilidad del pueblo, influyendo también en el arte; en Giotto por ejemplo. El movimiento de los espirituales franciscanos no termina con la muerte de Francisco, cruza la península de un lado a otro, manteniendo vivo el recuerdo del poverello ('pobrecillo') de Asís hasta el siglo siguiente; Dante compendiará la vida del santo en estupendos versos del Paraíso.

El Dolce Stil Nuovo reunió a un grupo de "fieles de amor" y formó una cofradía ligada por la amistad; los unía la pasión por la poesía,

${ }^{1}$ Doy en estos y en los siguientes versos una traducción literal. 
mantenida viva gracias a un diálogo constante en versos - aun militando en bandos políticos opuestos-, sin perder ninguno su individualidad poética. Los versos con que Dante responde en el canto XXIV del Purgatorio a Bonagiunta, quien en vida había criticado la poesía nueva, sintetizan sucintamente su poética personal, la cual solo en líneas generales puede aplicarse a los demás poetas:
I'mi son uno che quando
Amor mi spira, noto, e a quel modo
Ch'e'ditta dentro vo significando.
('Yo soy alguien a quien cuando el
Amor me inspira, anoto, y de la ma-
nera que me dicta voy significando')

Parecería que estos célebres versos ponen el acento sobre la espontaneidad expresiva, como lo consideraron los románticos del siglo pasado; sin embargo, el florentino más bien quiere subrayar la sinceridad con que obedece el dictado del amor, del sentimiento amoroso; mientras que el vo significando que concluye el sirventés enfatiza la elaboración a la que el poeta debe someter la inspiración, el duro oficio poético del que Dante tuvo alta conciencia. Un eco de esto se encuentra en el áspero verso con que Cavalcanti concluye un soneto en respuesta a la crítica de Guido Orlandi: "Amore ha fabbricato ciò ch'io limo" ("Amor ha fabricado lo que yo pulo con la lima'), que manifiesta la fidelidad al amor que "dicta" y la espontaneidad del "dictado" pero sin excluir la "lima", la exigencia de la labor formal rigurosa.

El sirventés dantesco antes citado puede servir como epígrafe al movimiento poético florentino y toscano, pero de ninguna manera supone una ideología amorosa común a sus poetas. La doctrina que sostiene el canto amoroso es diferente de uno a otro. Donna mi prega, pero ch 'eo voglio dire, de Guido Cavalcanti, nada tiene que ver con la canción dantesca Donne ch'avete ntelletto d'amore. En el primero está presente la dicotomía amorosa de ascendencia platónica entre el amor terrenal y el amor celestial, reelaborada por el neoplatónico Plotino, quien se preguntaba si el amor es un dios o un demonio, o 
bien una pasión del alma o los dos conjuntamente. Cavalcanti, sin negar el amor espiritual, acentúa el carácter irracional y violento del amor, en donde el deseo erótico se mezcla a menudo con el instinto de muerte:

Donna me prega, — per ch'eo voglio dire

D'un accidente que sovente è fero

Ed è sì altero - chè chiamato amore

Di sua potenza segue spesso morte.

('Una dama me ruega para que yo me preste a hablar de un hecho a menudo feroz y tan altivo, que es llamado amor. De su poder sigue a veces la muerte').

En esta canción doctrinal sobre la naturaleza del amor, traducida y comentada por Ezra Pound en los primeros decenios del siglo xx, Cavalcanti da forma dramática al tema del amor destructor, al contrario de un Dante o de un Cino da Pistoia.

La inteligencia florentina, aristocrática per altezza d'ingegno y desdeñosa del vulgo y de las compañías triviales, profesa el platonismo amoroso; esa ideología renuncia a la realización carnal mediante una catarsis de la pasión que se vuelve contemplación estática de la belleza espiritual femenina. El poeta y dantista italiano Edoardo Sanguineti afirma que la renuncia tuvo que ser un aprendizaje doloroso para el temperamento sensual y carnal de los grandes protagonistas del Eros lírico florentino. No creo que esa catarsis haya funcionado fuera de la obra literaria, que haya pasado a la vida privada de sus autores. No es casual el hecho de que Dante haya puesto en el Purgatorio al iniciador de la nueva poesía de "Amor gentile", Guido Guinizzelli, precisamente en el cerco VII, el de los lujuriosos. El mismo autor de la Divina comedia fue, si creemos a La vida de Dante de Boccaccio - ferviente lector del gran florentino-, un hombre apasionado y hasta lujurioso. Dante conoció bien la otra vertiente del amor, y sus Rime petrose constituyen la contraparte del Dolce Stil Nuovo. Es ejemplar la canción: 
Così nel mio parlar voglio esser aspro

Com'è ne li atti questa bella petra.

('Así en mi hablar quiero ser áspero, como es en sus actos esta bella piedra'),

aun cuando se acepte la interpretación alegórica de la mujer-piedra como Florencia o la Iglesia.

Las turbaciones del amor juvenil, la dulzura, lo inefable, el éxtasis doloroso de la Vita Nuova se convierten, de las rimas pedrosas de Dante, en la brutalidad amorosa cercana al impulso "animal" que lleva al adolescente Stephen Dedalus de calle en calle - "la lengua pegada al paladar" - en la oscuridad de la noche, para buscar satisfacción en los brazos de una que otra prostituta.

En el ámbito de la Vita Nuova falta la vertiente del amor erótico. Dante omite el llamado de la carne, que no puede prorrumpir donde pasa la tanto gentile e tanto onesta Beatriz, amor adolescente que con su sola presencia elimina toda intrusión sexual. El amor de Dante se alimenta de saludos, miradas, sonrisas, alabanzas; en fin, los tópicos del amor dulcestilnovista. Falta en la Vita Nuova la representación naturalista del deseo carnal que la tradición cristiana, desde San Pablo, ha condenado. El deseo y la pasión faltan, pero no porque - ya se dijo - Dante no los haya sentido y vivido o porque haya sido incapaz de expresarlos; ello puede verse no solo en sus rimas sino también en el Infierno de la Comedia, en donde encontramos varios condenados por lujuria y adulterio. Sin embargo, en ese infierno hórrido y pavoroso, primera etapa del viaje iniciático dantesco destinado a la salvación de la cristiandad, lleno de descripciones de crudo realismo, cuando el poeta se detiene en el estupendo episodio de Paolo y Francesca (canto V del Infierno) no hace una sola referencia cruda a la historia de adulterio, narrada por Francesca con casta sencillez. Ella es el polo opuesto de Beatriz, es el amor-pasión destructor del que habla Cavalcanti. En los versos de la narración, Dante deja vibrar sugerencias que el lector puede integrar para entender aquellos dubbiosi desiri ('deseos dudosos') que el poeta se muestra tan interesado en conocer cuando se dirige a Francesca. Constituyen 
una crítica implícita al roman courtois, cuya lectura había perturbado a los dos amantes hasta inducirlos al pecado:

Quando leggemmo il disiato riso

Esser baciato da cotanto amante

Questi, che mai da me non fia diviso

La bocca mi baciò tutto tremante.

Galeotto fu il libro e chi lo scrisse:

Y Francesca termina su narración con versos sombríos y alusivos:

Quel giorno più non vi leggemmo innanzi.

('Cuando leímos cómo la deseada sonrisa fue besada por un tal amante, este, que ya nunca jamás se separará de mí, la boca me besó todo temblando. Galeoto fue el libro y quien lo escribió: ese día ya no seguimos leyendo')

Fue la lectura del roman courtois de Ginebra y Lanzarote la que los perdió. Al terminar Francesca su relato, Dante cae desmayado. No es solo por piedad, sino por la identificación con los dos amantes: la lujuria es el pecado al que más teme, porque él mismo percibe su fragilidad ante la pasión erótica.

La Vita Nuova es la historia del amor del joven Dante, cuyo primer encuentro con Beatriz se remonta a los nueve años del poeta. La prosa se intercala con poesía en la que Dante glosa, al modo de los razos occitanos, las circunstancias en que nació y explica hasta cierto punto el contenido de sus poemas. Tres son los protagonistas: Dante, Beatriz y Amor. El Amor, como vivencia interior, está personificado, según la costumbre medieval de dar consistencia corpórea a los sentimientos; ello permitió a Dante dramatizar sus estados psíquicos a través de figuras visuales, plásticas. El sueño tenebroso de Amor, quien lleva en brazos a Beatriz y ofrece el corazón a Dante para que lo coma, como en un sacrificio ritual, es de derivación bíblica. De origen bíblico y clásico son también los recursos retóricos: la para- 
taxis del discurso, el polisíndeton, la prolepsis, las reiteraciones y los paralelismos, el uso de gerundios, de infinitivos sustantivados; todos ellos contribuyen a crear una atmósfera visionaria, profética, de ensueño, de misterio, de repentinas apariciones, de desaceleraciones que intensifican la visión: el éxtasis místico. En cambio, para analizar los efectos físicos que el amor produce en el amante: el temblor - ya el viejo Platón y la poetisa Safo habían hablado del temblor provocado por la vista de la persona amada-, la palidez, la aceleración del pulso, la mudez... Dante recurre a la ciencia médica de su tiempo, que se estudiaba en las universidades de Salerno y de Bolonia.

La Vita Nuova, dice Benedetto Croce, es una novela teológica, y lo es también el Retrato del artista adolescente de Joyce, quien se había formado en la escuela del viejo De Aquino en dos colleges jesuitas de Dublín. En la novela predominan las discusiones sobre Aristóteles y la Escolástica, Tomás de Aquino sobre todo, en un ambiente dominado por la enseñanza de Ignacio de Loyola, un ambiente contrarreformista que Stephen terminará por cuestionar y rechazar. Cuando, por ejemplo, uno de sus compañeros le dice que Giordano Bruno, a quien Stephen admiraba profundamente, había sido un "terrible heretic" ("terrible hereje'), él contesta secamente que "he was terribly burned" ('había sido quemado de manera terrible'). Además de novelas teológicas, la Vita Nuova y el Artista adolescente son retratos juveniles, autobiografías de iniciación amorosa y también artística: las primeras turbaciones frente al misterio que representa el amor, máxime para un adolescente; el descubrimiento de la vocación artística y la elaboración de una poética personal; las reflexiones sobre las vivencias de la adolescencia; en fin, el balance de la primera parte de la vida y el anuncio solemne de las obras futuras.

Al contrario del Retrato de Joyce, que se desarrolla en un contexto histórico preciso, la Vita Nuova no hace referencia o alusión alguna al escenario histórico, a la situación compleja de las últimas décadas del siglo xII, uno de los periodos más críticos y apasionados de la cultura italiana, de luchas internas en las comunas y contiendas entre el Imperio y el Papado en las que Dante, al igual que Cavalcanti, participó pagando con el exilio de por vida.

Para narrar su amor a Beatriz, medio de auto perfección y conocimiento, Dante utiliza la primera persona, que antes habían usado 
San Agustín en Las confesiones y Boecio en La consolación de la filosofía. El yo de Dante no es solo el yo empírico, sino que coincide con el yo universal, según la tendencia medieval de ver los exempla en la persona o en sus circunstancias para representar, más allá de la contingencia, la calidad ejemplar de los acontecimientos, su simbolismo.

Al contrario que en la Vita Nuova, en el Retrato de Joyce es central la experiencia del amor en su polaridad atormentadora: el amor sensual, el instinto carnal en conflicto con la ley religiosa, y el amor espiritual. Las figuras de la prostituta y la virgen se alternan: en primer plano la revelación punzante del sexo y, en lo profundo del ser de Stephen, la presencia de la adolescente amada, que le impide levantar los ojos hacia Ella (She).

¿Qué tiene que ver la Vita Nuova con Stephen Dedalus, perseguido por la lujuria y las llamas infernales a las que se siente irremediablemente condenado? El realismo del tercer capítulo del Retrato, el largo sermón del jesuita sobre el pecado y el castigo infernal, corresponden más bien al Infierno de la Comedia, pero aún más impresionante, puesto que Dante se encuentra en el infierno no como condenado, sino como viajero acompañado por Virgilio, que se instruye sobre los pecados y castigos de los que está inmunizándose e inmunizando a sus lectores, mientras que Stephen vive amenazado por las llamas infernales; por ello la presencia del infierno, ya se dijo, es más amenazadora. Lleno de miedo y de remordimientos, se somete a una severa autodisciplina de devoción: plegarias, misas, ayunos, humildad. Es cuando el director de su college le sugiere abrazar el sacerdocio. Puesto ante el dilema, Stephen siente que no es este su camino $\mathrm{y}$, descorazonado, emprende uno de sus largos vagabundeos hasta hallarse en la playa, meditando. Allí, el encuentro con los estudiantes que nadan y lo llaman alegremente desde el mar - "Dedalus! Bous Stephanoumenos! Bous Stephaneforos!"-, así como la aparición en el mar de la muchacha parecida a un ave, constituyen el llamado de la vida: "This was the call of life to his soul not the dull gross voice of the world of duties and despair, not the inhuman voice that had called him to the pale service of the altar" ('Este era el llamado de la vida, no la voz grosera y turbia del mundo lleno de deberes y de pesares que le había llamado al lívido servicio del altar'). "And new wild 
life was singing in his veins" ('Y una nueva vida salvaje empezó a cantar en sus venas'). Decide alejarse de la vida religiosa y elegir su camino sin vacilaciones.

En este encuentro de Stephen con la vida, Joyce recurre a la técnica de la epifanía, que es, según lo que él mismo más o menos dice, la irrupción espiritual que surge de repente en medio de discursos o gestos triviales, resultado de largos procesos mentales, meditaciones, como las que acompañan a Stephen en el vagabundeo que lo lleva a la playa. Son estos momentos epifánicos los que deciden la liberación de su alma: "His soul had arisen from the grave of boyhood, spuring her graveclothes" ('Su alma se acababa de levantar de la tumba de su infancia, apartando de sí sus vestiduras mortuorias'). Así describe Joyce la aparición epifánica de la muchacha-ave en medio de la corriente, su rostro de niña marcado por el prodigio de la belleza mortal: "A wild angel had appeared to him, the angel of mortal youth and beauty, an envoy from the fair courts of life, to throw open before him in an instant of extasy the gates of all the ways of error and glory" ("Un ángel salvaje se le había aparecido, el ángel de la juventud y la belleza mortal, enviado por el tribunal estricto de la vida para abrirle de par en par, en un instante de éxtasis, la puertas de todos los caminos del error y de la gloria'). La mujer de la playa ya no es el ángel de celestial belleza, enviado del cielo para miracol mostrare, sino un ser de belleza terrenal, en antítesis con el ángel estilnovista del que Stephen se despide.

Si en los estilnovistas, Dante sobre todo, la mujer es el trámite para la perfección, mediadora entre el alma del hombre y Dios, realización de su anhelo hacia lo alto, en Stephen se convierte en la intermediaria que lo reconcilia con la vida y lo aleja de la fe como constricción. La aparición de la muchacha-ave que preanuncia el próximo viaje de Stephen parece resolver el drama de su conciencia disociada e integrar la dualidad amorosa en una sola imagen.

El encuentro, al final del Retrato, con la muchacha que ama y a quien no da nombre - la llama solamente She (Ella) — consolida el episodio de la playa. Intermitente y fugitiva aparición que enmudece la lengua de los hombres, She es la "Beatriz" de un college embebido de teología, cuyos encuentros llenan a Stephen de terror y éxtasis que se vuelven epifanías. La aparición de She saliendo de la biblioteca, 
que Joyce describe con ritmo lento y estático, tiene un sabor estilnovista, que recuerda los encuentros de Dante con Beatriz:

She passed out from the porch of the library and bowed across Stephen in reply to Cranly's greetings. He also? Was there not slight flush on Cranly's sheek? Or had it come forth at Temple's words? The light had waned. He could not see. [...] She had passed through the dusk. And therefore the air was silent save for one soft hiss that fell. And therefore, the tongues about him had ceased their babble. Darkness was falling. [...] A trembling joy, lambent as a faint light, played like a fairy host around him. But why why? Her passage through the darkning air?

('Ella pasó, saliendo de la biblioteca e hizo una inclinación para responder por detrás de Stephen al saludo de Cranly. ¿También él? ¿No había un ligero rubor en las mejillas de Cranly? ¿O procedía de las palabras de Temple? La luz había desaparecido y no lo podía ver. [...] Ella había pasado entre el crepúsculo. Y por todo esto estaba silencioso en el aire, salvo el suave siseo que caía de la ventana. Y por eso, las lenguas habían cesado también su cháchara. Estaba cayendo la obscuridad. [...] Una alegría temblorosa, como una caricia de pálidas luces danzaba una danza de espíritus encantados en torno a él. ¿Qué era? ¿Su pasaje a través del aire crepuscular?')

Confrontemos ahora la prosa de Joyce con la poesía estilnovista, cuyos tópicos y estilemas utiliza el irlandés. Al inicio de la larga frase citada Joyce usa el verbo to pass, passare en italiano, que forma parte del léxico del Dolce Stil Nuovo y que encontramos como incipit en varios sonetos estilnovistas.

Por ejemplo, el de Guinizzelli:

Passa per via adorna e sì gentile

('Pasa por la calle adornada y tan gentil') 
El de Cavalcanti:

Passa la gran beltate e la piagenza

De la mia donna...

('Pasa la gran hermosura y la gracia de mi amada')

Otro soneto del Cavalcanti:

Ch'è questa che ven, ch'ogn'om la mira

Che fa tremar de claritate l'aire?

('¿Quién es ésta que viene, que todo hombre la mira y hace temblar de claridad el aire?’)

Los versos iniciales de un soneto de Dante en la Vita Nuova:

Ov'ella passa, og'om ver lei si gira

E cui saluta fa tremar lo core

si che bassando il viso, tutto smore.

('Donde ella pasa cada hombre voltea, y a quien saluda se le estremece el corazón, así que bajando el rostros, palidece todo')

En otro soneto de la Vita Nuova, Dante subraya el temblor y el silencio que la mujer amada suscita a su alrededor:

Tanto gentil e tanto onesta pare

La donna mia quand'ella altrui saluta

Ch'ogni lingua deven tremando muta

E li occhi no l'ardiscon di guardare.

('Tan gentil y honesta muéstrase la dama mía cuando un saludo ofrece, que toda la lengua temblando enmudece, y los ojos no se atreven a mirarla') 
Pero hay algo más en común entre Dante y Joyce: el disimulo, el ocultamiento amoroso. Después del encuentro con She, Stephen se aleja para ocultar a los demás su turbación: "He walked away slowly towards the deeper shadows at the end of the colmnade...to hide his revery from the students whom he had left..." ('Se alejó lentamente hacia el extremo de la columnata donde las sombras eran más intensas, para ocular su ensueño a los estudiantes que había dejado atrás...'). Exactamente como Dante en la Vita Nuova, quien oculta sus pensamientos íntimos para defenderlos de la curiosidad de la gente que se burla de lo intangible, lo que no se puede entender, profanando los sentimientos más sagrados.

Sin embargo, las páginas de sabor estilnovista del Retrato concluyen abrupta e irónicamente en escarnio, cuando interfiere un irreverente y simbólico piojo en el cuello de Stephen, despertándolo de su sueño.

En el último y breve capítulo de la Vita Nuova, Dante presenta la visión estática de su amada muerta, y se despide de la primera etapa de su vida prometiendo una obra dedicada a la exaltación de Beatriz cuando pueda hacerlo de manera más digna, infino a tanto, dice, "io potesse degnamente parlar di lei... dicer di lei quello che non fu detto d'alcuna" ('hasta cuando yo pueda hablar de ella... decir de ella lo que no se ha dicho de ninguna otra'). La obra concluye con una serenidad, que contrasta con la angustia y el dolor de los breves capítulos anteriores.

El final del Retrato es también sereno, seguro. Stephen registra en breves notas de su diario la decisión de cortar con su vida pasada y abandonar Irlanda. Encuentra por última vez a la muchacha amada y le comunica su decisión y, como ella no lo entiende, "he turned off that valve at once and opened the spiritual-heroic refrigerating apparatus invented and patented in all countries by Dante Alighieri" ('cerró la llave del grifo y abrió el aparato refrigerante heroico-espiritual inventado y patentado en todos los países por Dante Alighieri'). Stephen saldrá del mundo sofocante de Dublín; irá, como dice, "to encounter for the millionth time the reality of experiencie and to forget in the smithy of my soul the uncreated conscience of my race" ('a buscar por millonésima vez la realidad de la experiencia y a forjar en la fragua de mi espíritu la no creada conciencia de mi raza'). 
Este rápido recorrido podría surgir en el lector la duda de si las referencias del Retrato al sentimiento amoroso del Dolce Stil Nuovo son fruto de una coincidencia - lo cual por cierto confirmaría la continuidad en el tiempo del amor cortés en sus variantes estilnovistas- y no de una referencia intencional. Por mi parte, después de una atenta confrontación de ambas obras quedo convencida de que Joyce quiso remontarse a una tradición que conformó por siglos el alma europea, para explicarse (se ha dicho que su Retrato es en buena parte autobiográfico) a través de su protagonista Stephen Dedalus la complejidad del sentimiento amoroso que lo acosaba.

\section{REFERENCIAS}

Alighieri, Dante, La Vida Nueva (ed. bilingüe), México, Universidad Nacional Autónoma de México, 1965.

Benedetto, Luigi di (ed.), Rimatori del Dolce Stil Novo, Bari, Laterza, 1960.

Joyce, James, A Portrait of the Artist as a Young Man, New York, The Viking Press, 1973.

Singleton, Charles, Saggio sulla 'Vita nuova', Bologna, Il Mulino, 1968.

ANNUNZIATA Rossi 